\title{
Logical modelling and analysis of the budding yeast cell cycle Adrien Fauré $^{* 1}$, Claudine Chaouiya ${ }^{1}$, Andrea Ciliberto ${ }^{2}$ and Denis Thieffry ${ }^{1}$
}

\author{
Address: ${ }^{1}$ Université de la Méditerranée \& INSERM ERM206, Marseille, France and ${ }^{2}$ IFOM, Milano, Italy \\ Email: Adrien Fauré* - faure@tagc.univ-mrs.fr \\ * Corresponding author
}

from Third International Society for Computational Biology (ISCB) Student Council Symposium at the Fifteenth Annual International Conference on Intelligent Systems for Molecular Biology (ISMB)

Vienna, Austria. 21 July 2007

Published: 20 November 2007

BMC Bioinformatics 2007, 8(Suppl 8):PI doi:I0.1 I86//47|-2105-8-S8-PI

This abstract is available from: http://www.biomedcentral.com/I47I-2105/8/S8/PI

(c) 2007 Fauré et al; licensee BioMed Central Ltd.

\section{Biological background}

The budding yeast cell cycle core engine has been modelled in great detail, most notably by the groups of Béla Novak and John Tyson, using a differential formalism. Several models focusing on different regulatory modules have been developed. In this respect, the use of a logical formalism facilitates the development of more integrated models, through the articulation of control modules to the core engine. Such integrated models are difficult to build with the differential formalism due to the lack of quantitative data, as well as to numerical instabilities inherent to large non linear systems.

\section{Logical modelling of cell cycle regulatory modules}

Relying on the logical framework defined by Thomas and Kaufman [1], we use GINsim, the modelling software developed in our team [2] to integrate the morphogenesis checkpoint module to the core model of the yeast cell cycle published by Chen et al. [3] (see also [4] for an application on the Mammalian cell cycle).

Our current logical model recapitulates the wild type succession of events as presently characterised. We are now adjusting the model parameters to account for all mutant phenotypes described together with the original differential model [3]. At this point we focus on Knock Out (KO) mutants and on strong gene over-expressions.

Our logical simulations provide consistent results for two thirds of the 90 mutants already tested. The remaining problematic cases involve regulatory genes such as Sic1 and Cdh1, whose parameterisation is very complex. We are currently implementing in GINsim the possibility to define the parameters in the form of logical formulas to overcome this problem.

In parallel with our model of the budding yeast cycling core, we are developing a logical model of the morphogenesis checkpoint, inspired by the work of Ciliberto et al. [5]. This module is expected to produce a stable state with active Clb2 when the checkpoint is off, and when the checkpoint is on, Clb2 activation should be delayed, to prevent the formation of dinucleate cells. Still, the arrest is not complete, and after a while the checkpoint can be overcome. In our model, this relates to an increase of mass. Clb2 is then activated and the cell can complete nuclear division, becoming dinucleate.

This module has been designed to fit the wild-type behaviour, as well as that of the swe $1 \Delta$, mih $1 \Delta$ and hsl $1 \Delta$ mutants. Interestingly, the double mutants mih $1 \Delta$ hsl $1 \Delta$ and mih $1 \Delta$ swe1 $\Delta$ also exhibit the expected behaviour. Other mutant phenotypes listed or predicted in $[3,5]$ have still to be tested.

\section{Conclusions and prospects}

The two models have then been connected together. Preliminary stable state analysis shows that the coupled model retains the properties of the two modules. A more thorough analysis should confirm this result. At the present time, we still have to tune these models to fit all 
the mutant phenotypes. In the longer term, we plan to model other checkpoints and connect the resulting modules to our cell cycle core model. Finally, we also plan to systematically apply regulatory circuit analysis and model-checking approach to the resulting model.

\section{References}

I. Thomas R, Kaufman M: Multistationarity, the basis of cell differentiation and memory. II. Logical analysis of regulatory networks in terms of feedback circuits. Chaos 200I, II:I80-95.

2. Gonzalez AG, Naldi A, Sanchez L, Thieffry D, Chaouiya C: GINsim: a software suite for the qualitative modelling, simulation and analysis of regulatory networks. Biosystems 2006, 84:9I- 100.

3. Chen KC, Calzone L, Csikasz-Nagy A, Cross FR, Novak B, Tyson Jj: Integrative analysis of cell cycle control in budding yeast. Mol Biol Cell 2004, 15:384I-62.

4. Fauré A, Naldi A, Chaouiya C, Thieffry D: Dynamical analysis of a generic Boolean model for the control of the mammalian cell cycle. Bioinformatics 2006, 22:e I24-3I.

5. Ciliberto A, Novak B, Tyson Jj: Mathematical model of the morphogenesis checkpoint in budding yeast. J Cell Biol 2003, 163:1243-54.

Publish with Bio Med Central and every scientist can read your work free of charge

"BioMed Central will be the most significant development for disseminating the results of biomedical research in our lifetime. "

Sir Paul Nurse, Cancer Research UK

Your research papers will be:

- available free of charge to the entire biomedical community

- peer reviewed and published immediately upon acceptance

- cited in PubMed and archived on PubMed Central

- yours - you keep the copyright 